\title{
Universidad y campo laboral: las mujeres en el ámbito de la comunicación
}

\author{
Adrián Hernández Vélez \\ Michel Montiel Meléndez
}

University and labor field: women in the field of communication

\begin{abstract}
RESUMEN
Desde la perspectiva de las trayectorias profesionales, nos acercamos a la incursión de las mujeres en el campo de la comunicación en el estado de Tlaxcala (México). La investigación tuvo un soporte epistémico de tipo hermenéutico-fenomenológico y la arquitectura metodológica correspondió a un estudio de caso. Entre los hallazgos se identificaron tres perfiles: pioneras, con trayectoria consolidada y noveles. También se encontró una relación de cimentación mutua entre el gremio de comunicólogos y la Universidad del Altiplano, que se estableció como la primera institución de educación superior privada y bastión en la formación de egresados con este perfil profesional.
\end{abstract}

Palabras clave: comunicólogas, identidad y trayectoria profesional.

\section{ABSTRACT}

From the perspective of professional careers, we approach the incursion of women in the field of communication in the state of Tlaxcala (Mexico). The research had epistemic support of a hermeneutic-phenomenological type and the methodological architecture corresponded to a case study. Among the findings, three profiles were identified: pioneers, with a consolidated career and new ones. Also, a mutual foundation relationship was found between the community of communication experts and the Universidad del Altiplano, which was established as the first private higher education institution and bastion in the training of graduates with this professional profile.

Keywords: communicators, identity and professional career. 


\section{INTRODUCCIÓN}

La incorporación de las mujeres en los medios de comunicación, en mayor sentido, se ha desarrollado explotando su imagen estereotipada conforme a roles tradicionales, sexistas y utilitaristas (Burkle, 1997 y Ortiz, 2001), por eso, en el marco global, han emergido espacios que promueven el reconocimiento de su capacidad profesional, por ejemplo la Plataforma de Acción Beijing, que desde 1995 se pronunció por valorar el talento intelectual y ejecutivo de las mujeres, impulsando su incorporación en cargos trascendentales de las empresas (ONU, 1996) y en múltiples ámbitos sociales y laborales desde los cuales se construyen narrativas soportadas en la igualdad de género como condición de vida cotidiana (OIT, 2017).

En México, el Instituto Nacional de las Mujeres (INMujeres, 2017) señaló la existencia de 1,709 radiodifusoras, en las cuales las mujeres encontraron un espacio de desarrollo equitativo con relación a los hombres, sin embargo, aunque ha sido reportado como el medio en el que han logrado su mayor incorporación, solo ocuparon nueve de 31 cargos directivos existentes entre las 10 principales cadenas radiofónicas, y de los 18 principales periódicos del país solo ocuparon 16 de 140 cargos directivos, mientras que de cada 100 noticias, 24 fueron presentadas por mujeres.

Por su parte, el Instituto Mexicano de la Competitividad (IMCO) reportó que durante el 2018 desarrollaron estudios en el área de las ciencias de la comunicación 270,309 personas, situándose en el lugar 14 entre los programas con mayor matrícula, lo que representó el 2.2\% del total de personas con carrera. El 55\% correspondió a mujeres y el $45 \%$ se trató de hombres. La tasa de ocupación para este periodo fue del 96\%, aunque de estos el 29.4\% trabajó en la informalidad, lo que implicó el desempeño de funciones ajenas a su perfil de egreso. Los sectores en los que laboraron abarcaron el de servicios profesionales, científicos y técnicos (16.7\%), información en medios masivos (16.5\%), servicios educativos (11.5\%), en el comercio al por menor $(10.7 \%)$ y en actividades gubernamentales y de organismos internacionales $(10.5 \%)$ (IMCO, 2020).

Adrián Hernández Vélez. Profesor en el Instituto de Profesionalización del Magisterio Poblano, Puebla, México. Es doctor en Educación por la Universidad Autónoma de Tlaxcala (UATx) y colabora en los posgrados en Educación de la Universidad de las Américas Puebla (UDLAP) y la Universidad del Valle de Puebla. Entre sus publicaciones más recientes se encuentran los libros Repensar la educación en México. Textos a deliberación (coord., 2019) y La investigación educativa en la Universidad Autónoma de Guerrero (coord., 2020). Correo electrónico: ahv31@hotmail.com. ID: https://orcid.org/0000-0003-0940-010X.

Michel Montiel Meléndez. Profesora en la Universidad del Altiplano y en la Universidad del Valle de Tlaxcala, Tlaxcala, México. Es licenciada en Ciencias de la Comunicación por la Universidad del Altiplano y tiene estudios de maestría en Pedagogía por la Universidad Popular Autónoma del Estado de Puebla (UPAEP). Obtuvo el tercer lugar en el concurso de trabajos recepcionales en comunicación CoNEIC 2018. Correo electrónico: michelmontiel09@gmail.com. ID: https://orcid.org/0000-0001-7618-4879. 
En cuanto al contexto empírico de esta investigación, se situó en el ámbito de los medios de comunicación en el estado de Tlaxcala, en donde existe una población de 1'169,936 habitantes, de los cuales 604,161 son mujeres (INEGI, 2017). Se cuenta con seis radiodifusoras, cuatro diarios impresos ${ }^{1}$ y cinco canales de televisión (SECTE, 2019). La mayoría de los medios de comunicación se encuentran instalados en seis municipios: Apizaco, Calpulalpan, Huamantla, Santa Ana Chiautempan, San Pablo del Monte y Tlaxcala capital. Los profesionales de este campo están agrupados en dos organizaciones: la Unión de Periodistas del Estado de Tlaxcala (UPET) y la Asociación de Mujeres Comunicadoras de Tlaxcala (AMCT).

Considerando estos referentes como intención de generación de conocimiento, se buscó responder quiénes son las mujeres que participan en los medios de comunicación, así como identificar las diferentes etapas que se han presentado en el desarrollo de su profesión y determinar cómo se construyó la relación entre la Universidad del Altiplano y la conformación del ámbito de la comunicación como campo laboral en la entidad.

\section{Posicionamiento teórico}

Es posible percatarse de la indefinición semántica de la palabra "trayectoria", por eso se recuperó la propuesta de Jiménez (2005), quien afirmó que consiste en las distintas "etapas que vive el individuo después de finalizar su formación en una determinada profesión o al insertarse en una actividad laboral u oficio, en cuanto a lo profesional, laboral, económico y social" (p. 2). Existen diferentes tipos de trayectorias, por ejemplo las laborales, abordadas en trabajos clásicos como los de Freidin (1996) y Aparici (2004) y otros recientes como los de Alós-Moner (2008), Neffa, De la Garza y Muñiz (2009) y Muñiz (2012). Estas corresponden a las secuencias de experiencias o posiciones laborales que ocupa una persona a través del tiempo. También las trayectorias educativas o académicas, ubicadas en la obra de Velázquez (2007), Blanco, Solís y Robles (2014), Filardo (2016) y Juliá (2018), las cuales consisten en la secuencia de eventos que se suscitan en la vida de una persona entre el ingreso y el egreso a la educación formal. Las trayectorias de vida han sido estudiadas por Guerreiro y Abrantes (2005), así como por Caballero y García (2007), aunque destaca el concepto de Bourdieu (1997), para quien consisten en posiciones que ocupa una misma persona en un espacio en movimiento y en transformación, es decir, se trata de los eventos de diferente naturaleza, individual y social, que van conformando su biografía.

1 La Secretaría de Comunicaciones y Transportes del Estado de Tlaxcala informa que los principales medios de comunicación locales son El Sol de Tlaxcala, La Jornada Oriente, Sintesis de Tlaxcala-Puebla y ABC Noticias. En cuanto a los canales de televisión, reporta cinco y dos estaciones complementarias, no obstante, aunque indica que son de señal abierta, su cobertura es municipal, por lo que el acceso principalmente se obtiene a través de sistemas de paga. 
Conforme a Freidin (1996), las trayectorias laborales se dividen en dos enfoques, uno vincula su existencia a la conclusión de un plan de estudios y a la posterior incorporación de los egresados al mundo laboral (trayectorias profesionales). El otro enfoque establece la noción de ocupación ajena a la conclusión de estudios profesionales, por lo que su incursión no depende de un perfil de egreso (trayectorias laborales). En general, ambos enfoques indagan cómo incursionan las personas en una ocupación dentro del mercado laboral, respondiendo a las características bajo las cuales desempeñan sus funciones y a las formas en que enfrentan situaciones de movilidad interna y externa, sin embargo, siempre debe tenerse en cuenta la posibilidad de no alcanzar a conocer plenamente la realidad de los actores sujetos a análisis (Valenti, 1997) ya que existen múltiples factores que determinan la configuración de las trayectorias, por ejemplo, los de tipo personal vinculados a un contexto concreto e incluso a la historicidad bajo la cual se construye (Oshige, 2016). Por otra parte, impactan los aspectos académicos que, entre otros, se ven afectados por imaginarios de estatus y calidad (Muñiz, 2012). Otros factores corresponden a la condición socioeconómica y al capital cultural, por mencionar algunos (Ministerio del Trabajo y Previsión Social, 2017).

En esta investigación se recuperó la noción de trayectoria profesional de Freidin (1996) y, conforme a Trejo (2010), a los sujetos de estudio se les clasificó en comunicólogas y comunicadoras. Las primeras estudiaron ciencias de la comunicación, por lo que son especialistas de la comunicología, habilitadas para incursionar en medios de comunicación y en otros ámbitos, por ejemplo, en el área de comunicación social de instituciones y empresas, impulsando desde el área de recursos humanos estrategias para fortalecer el clima laboral, también como asesoras políticas, entre otros ámbitos. En el caso de las comunicadoras, se desempeñan desarrollando únicamente funciones de información y, para fines de este estudio, conforman el sector que cuenta con estudios en campos distintos a la comunicación.

\section{Arquitectura metodológica}

El estudio tuvo una base epistémica de tipo fenomenológica-hermenéutica y una arquitectura metodológica cualitativa con diseño de estudio de caso, soportado en cinco ejes de análisis: elección vocacional, trayectoria, identidad profesional, condición de género y relación entre la Universidad del Altiplano y el campo laboral. Para la fenomenología, "la realidad no se analiza ni se explica, solo se describe bajo el argumento del retorno a la cosa misma porque todo cuanto se sabe del mundo, se sabe a partir de una experiencia del mundo" (Merleau-Ponty, 1994, p. 10). En cuanto a la hermenéutica, conforme a Gadamer (2007), constituye una actitud de disposición al encuentro con el otro a través del diálogo y una ruta de acceso al conocimiento a través de rutas distintas al método científico. 
En el proceso cualitativo, las informantes fueron localizadas mediante la consulta a expertos y el criterio de inclusión consistió en ubicar a las comunicólogas y comunicadoras que mantenían relación laboral con al menos un medio de comunicación reconocido en la entidad, tales como televisión, radio, medios impresos y digitales. Se entrevistó a 14 personas que atendieron la invitación, quienes fueron caracterizadas conforme a las categorías de análisis señaladas en la tabla 1. Se dialogó con una persona considerada como pionera, también con nueve mujeres con trayectoria profesional consolidada, entre las cuales se contó con seis comunicólogas y tres comunicadoras y, finalmente con tres comunicólogas noveles.

Tabla 1. Sujetos de estudio.

\begin{tabular}{|c|c|c|c|}
\hline Entrevistas & Perfiles & $\begin{array}{l}\text { Años de } \\
\text { trayectoria }\end{array}$ & Ocupación inicial \\
\hline Entrevista 1 & $\begin{array}{l}\text { Egresada en la licenciatura de periodismo. } \\
\text { Fundadora de la Universidad del Altiplano }\end{array}$ & 55 & $\begin{array}{l}\text { Reportera en medios } \\
\text { impresos y corresponsal }\end{array}$ \\
\hline Entrevista 2 & $\begin{array}{c}\text { Egresada en la licenciatura en Ciencias de la Comunicación-UDA } \\
\text { Fundadora de la Asociación } \\
\text { de Mujeres Comunicadoras de Tlaxcala (AMCT) }\end{array}$ & 28 & Rep \\
\hline Entre & $\begin{array}{c}\text { Egresada en la licenciatura en Ciencias de la Comunicación (UDA) } \\
\text { Primera mujer galardonada con la Presea Miguel N. Lira }\end{array}$ & 26 & $\begin{array}{l}\text { Reportera en } \\
\text { medios impresos }\end{array}$ \\
\hline Entrevista 4 & Egresada en la licenciatura en Ciencias de la Comunicación (UDA) & 26 & Reportera en televisión \\
\hline Entrevista 5 & Egresada en la licenciatura en Ciencias de la Comunicación (UDA) & 23 & Reportera en medios impresos \\
\hline Entrevista 6 & Egresada de la Licenciatura en Publicidad & 19 & Conductora en radio \\
\hline Entrevista 7 & Egresada de la licenciatura en Literatura Hispanoamericana & 19 & Conductora en televisión \\
\hline Entrevista 8 & Egresada de la Licenciatura en Antropología & 14 & Reportera en medios impresos \\
\hline Entrevista 9 & Egresada en la licenciatura en Ciencias de la Comunicación (UDA) & 13 & Reportera en radio \\
\hline Entrevista 10 & Egresada en la licenciatura en Ciencias de la Comunicación (UDA) & 12 & Reportera en medios impresos \\
\hline Entrevista 11 & Egresada en la licenciatura en Ciencias de la Comunicación (UDA) & 8 & Reportera en radio \\
\hline Entrevista 12 & Egresada en la licenciatura en Ciencias de la Comunicación (UDA) & 5 & Conductora de programa en radi \\
\hline Entrevista 13 & Egresada en la licenciatura en Ciencias de la Comunicación (UDA) & 3 & Asistente en radio \\
\hline Entrevista 14 & Egresada en la licenciatura en Ciencias de la Comunicación (UDA) & 3 & Reportera en medios digitales \\
\hline
\end{tabular}

Fuente: elaboración propia.

La entrevista consistió en un diálogo regulado por un guión semiestructurado (Kvale, 2011), cuya base se encuentra en la operacionalización de núcleos temáticos (ver tabla 2), conforme a los cuales fueron orientadas las intenciones de generación de conocimiento. Además de la comprensión de la identidad que permite señalar quiénes son las mujeres que laboran en el campo de la comunicación y cómo ha sido su trayectoria profesional, se buscó comprender el proceso de empoderamiento mutuo entre universidad y campo laboral. 
Tabla 2. Núcleos temáticos.

\begin{tabular}{ll}
\multicolumn{1}{c}{ Núcleos } & Propósitos \\
\hline Elección vocacional & Conocer los factores que determinaron la elección profesional y su fortalecimiento \\
& cuando ejercieron su profesión \\
\hline Trayectoria & Identificar las fases que viven las comunicadoras en su trayectoria profesional y laboral \\
& Identificar los obstáculos que enfrentan en el desarrollo de su profesión \\
& Analizar sus expectativas de éxito \\
\hline Identidad profesional & Determinar los ejes sobre los cuales construyen su identidad profesional \\
\hline Condición de género & Analizar la relación entre género y desarrollo profesional \\
\hline Relación universidad y campo laboral & Analizar la relación entre la Universidad del Altiplano y el desarrollo del \\
& campo laboral de la comunicación \\
\hline
\end{tabular}

Fuente: elaboración propia.

El diálogo permitió el acceso a las percepciones que tenían sobre los temas abordados, logrando su comprensión e interpretación con base en principios hermenéuticos gadamerianos soportados en el análisis del contexto, momento histórico y capital lingüístico, sin embargo, como recurso complementario, previo registro de voz y captura en texto, fue usado el software MaxQDA. En la tabla 3 se observa el proceso de análisis que se desarrolló auxiliado por el software. Tomando en cuenta la lectura de las entrevistas y atendiendo a la estructura planteada en la definición de núcleos temáticos, se recuperaron los fragmentos que concentraron la mayor carga de sentido y se procedió a establecer un debate entre los referentes con mayor consistencia e inconsistencia en cada tópico dialogado, generando la construcción de sentido a los datos.

Tabla 3. Proceso técnico-hermenéutico.

\begin{tabular}{|c|c|c|c|c|c|c|c|}
\hline Categoría & $\begin{array}{c}\text { Entrevista } \\
1\end{array}$ & $\begin{array}{c}\text { Entrevista } \\
2\end{array}$ & $\begin{array}{c}\text { Entrevista } \\
3\end{array}$ & $\begin{array}{c}\text { Entrevista } \\
\mathrm{N}\end{array}$ & $\begin{array}{l}\text { Consistencia de } \\
11 \text { a N } \\
\text { (fragmentos } \\
\text { representativos } \\
\text { por categoría) }\end{array}$ & $\begin{array}{l}\text { Inconsistencia de } \\
11 \text { a N } \\
\text { (fragmentos } \\
\text { representativos } \\
\text { por categoría) }\end{array}$ & $\begin{array}{l}\text { Interpretación } \\
\text { (debate entre } \\
\text { consistencia e } \\
\text { inconsistencia) }\end{array}$ \\
\hline $\mathrm{A}$ & Fragmento & Fragmento & Fragmento & Fragmento & $\begin{array}{l}\text { Ejemplo: Fragmento } \\
\text { de entrevista } 2\end{array}$ & $\begin{array}{l}\text { Ejemplo: Fragmento } \\
\text { de entrevista } 9\end{array}$ & $\begin{array}{l}\text { Interpretación } \\
\text { por categoría }\end{array}$ \\
\hline B & Fragmento & Fragmento & Fragmento & Fragmento & $\begin{array}{l}\text { Ejemplo: Fragmento } \\
\text { de entrevista } 7\end{array}$ & $\begin{array}{l}\text { Ejemplo: Fragmento } \\
\text { de entrevista } 1\end{array}$ & $\begin{array}{l}\text { Interpretación } \\
\text { por categoría }\end{array}$ \\
\hline $\mathrm{C}$ & Fragmento & Fragmento & Fragmento & Fragmento & $\begin{array}{l}\text { Ejemplo: Fragmento } \\
\text { de entrevista } 4\end{array}$ & $\begin{array}{l}\text { Ejemplo: Fragmento } \\
\text { de entrevista } 12\end{array}$ & $\begin{array}{l}\text { Interpretación } \\
\text { por categoría }\end{array}$ \\
\hline
\end{tabular}

Fuente: elaboración propia. 


\section{RESULTADOS Y DISCUSIÓN}

Identificamos tres perfiles de profesionales de la comunicación, los cuales fueron definidos con base en la revisión de tres criterios: aportaciones al campo de la comunicación, nivel de consolidación de su identidad profesional y nivel de estabilidad laboral. Las pioneras cuentan con más de 50 años de ejercicio profesional y sentaron las bases del periodismo local. El perfil de trayectoria consolidada fue determinado identificando las diferencias de logro respecto a los perfiles pionero y novel, por lo que agrupa a mujeres con más de 10 y menos de 50 años de incursión laboral, constituyendo el grupo más numeroso. Las mujeres con perfil novel tienen como máximo 10 años de trayectoria y aún no consolidan su identidad profesional y/o su estabilidad laboral. En este informe, primero se presenta un análisis general de los tres perfiles y posteriormente se profundiza en los hallazgos del grupo de mujeres con trayectoria consolidada ya que conformaron el sector que heredó el legado de las pioneras y fueron señaladas como el referente de éxito por parte del grupo novel.
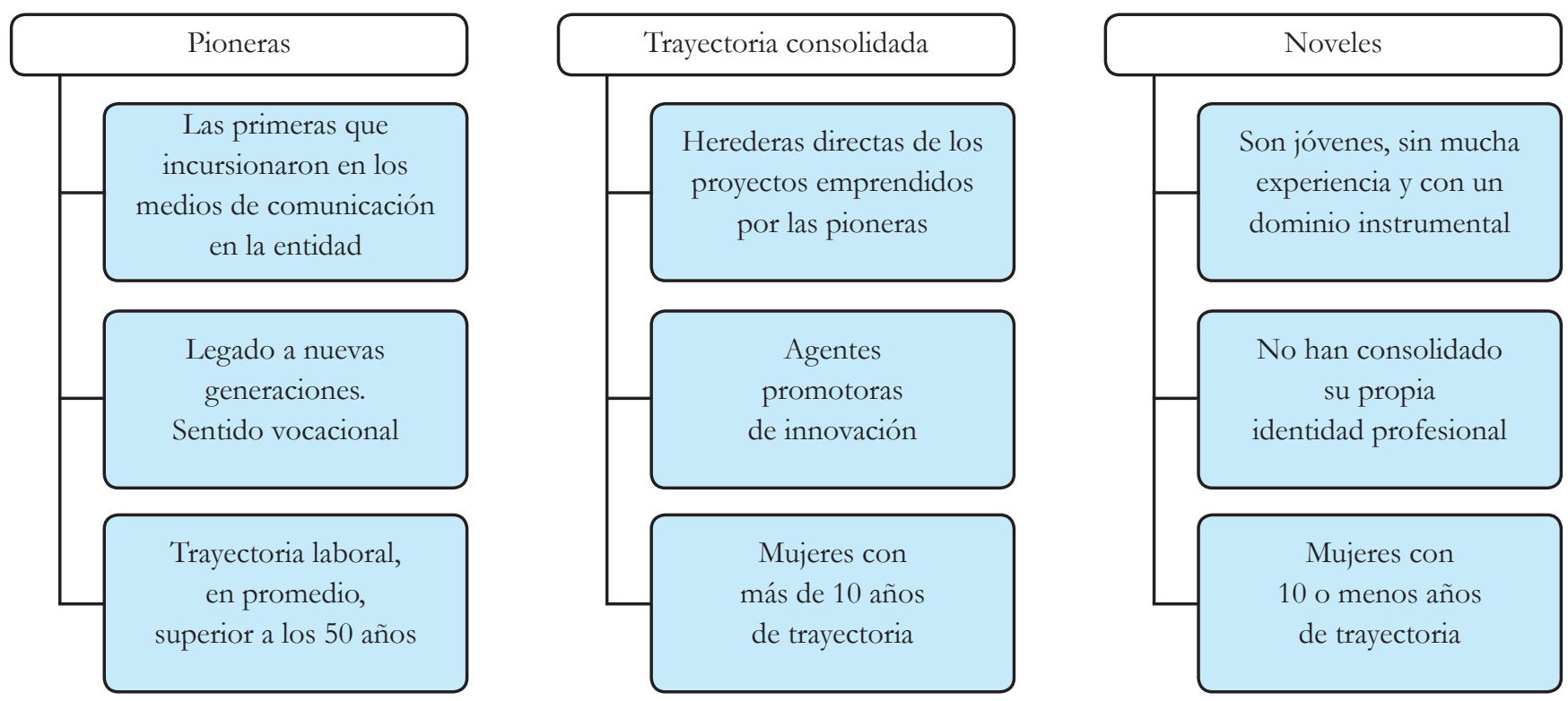

Fig. 1. Tipología de mujeres profesionales de la comunicación.

Fuente: elaboración propia.

\section{Las mujeres en los medios de comunicación}

Las pioneras iniciaron su trayectoria en el contexto nacional, debido a que en el entorno local existían pocos medios de comunicación, incluso enfatizaron en que no había instituciones que formaran profesionistas en esta área, lo cual les permitió ver en el gremio a colegas que no contaban con estudios en la materia, sino que se habían profesionalizado en la práctica. Su presencia fue reconocida por su incursión laboral y por el legado que dejaron a las siguientes generaciones, ya que establecieron 
las bases para la construcción del aparato teórico y práctico del campo profesional de la comunicación. En forma reiterada, el grupo de comunicólogas con trayectoria consolidada, así como el grupo de comunicólogas noveles, hicieron referencia a la Universidad del Altiplano (UDA) como la institución que marcó el horizonte de formación de especialistas de la comunicación en Tlaxcala. Se trata de una escuela fundada por la pionera con mayor trascendencia, quien comentó: "No fue la idea crear una universidad, sino crear una escuela de periodismo. Le pusimos Modesto González Galindo (...) entonces yo quería una escuela de máximo 40 alumnos para enseñar periodismo ya que no había periodistas profesionales en Tlaxcala" (1-BP).

Se trata de una periodista con más de 50 años de trayectoria y su legado consistió en la creación de un espacio de formación académica que se va posicionando por su calidad en el contexto regional. En 1986 fundó la Escuela de Periodismo que a partir de 1991 pasó a conformarse como asociación civil, estructurada por diferentes escuelas de educación superior y media superior. Para el año 2004 pasó a denominarse Universidad del Altiplano, teniendo como base a la licenciatura en Ciencias de la Comunicación ${ }^{2}$ (UDA, 2020).

Por su parte, las mujeres que tienen una trayectoria consolidada se asumieron como las herederas directas de los proyectos emprendidos por las pioneras. La mayoría son egresadas de la Universidad del Altiplano e iniciaron su ejercicio profesional en los medios que ahí les enseñaron. Les tocó vivir la transición de su labor centrada en los medios tradicionales hacia nuevas formas soportadas en el uso de medios digitales. Una entrevistada comentó: "Ya al estar independientes empezamos a buscar otras formas de mejorarlo y poco a poco se fue haciendo (...) surgimos a la par de otro medio digital aquí en Tlaxcala, no había más, y fue así como le seguimos” (4-BT).

Se trata de mujeres que, al igual que las pioneras, definieron una nueva época al aprovechar el desarrollo del internet y el uso de dispositivos tecnológicos para crear nuevas ofertas, sus propios medios de carácter digital.

En cuanto a la definición del perfil novel, se encontraron mayores referencias teóricas que orientaron su definición, por ejemplo, autores como Granados, Tapia y Fernández (2017) y Montes, Castillo y Oliveros (2017) afirman que los profesionistas nóveles en su mayoría son recién graduados, por lo que su antigüedad laboral es inicial, así que no cuentan con una identidad profesional consolidada y se sostienen en un proceso de aprendizaje permanente sobre el aparato instrumental y crítico de su campo de acción. Además de estos rasgos, las comunicólogas entrevistadas, en su mayoría, también sostuvieron una línea de formación heredada de la Universidad del Altiplano y encontraron en las mujeres con trayectoria consolidada sus referentes a seguir, por lo que construyeron imaginarios de éxito soportados en los logros que estas han alcanzado. Una entrevistada señaló:

2 En adelante la licenciatura en Ciencias de la Comunicación será referida como CICOM. 
Los medios tradicionales están saturados y pienso que la mayoría egresamos con la idea de participar en radio y televisión y no tanto en otras áreas que nos dicen en el perfil de egreso [...] en las mismas clases le dan más importancia a radio y T.v., pero es difícil, sales con toda la actitud y ya al buscar entrar a trabajar no está fácil, así que buscamos los medios digitales y pienso que también están tomando mucha presencia, así que vemos cómo le hicieron [...] las que nos dieron conferencias y tienen sus propios medios [13-BN].

Son jóvenes, sin mucha experiencia, con un dominio instrumental heredado de su formación universitaria y de su incursión en prácticas profesionales. En este sentido una entrevistada comentó: "Estoy aprendiendo, es práctico y obvio, te llevan ventaja, una es la nueva y tratas de aprender de los que saben, qué hacen, cómo lo hacen, qué les funciona, cosas asî́" (14-BN). Se observa que no han logrado su estabilidad laboral y no han consolidado su propia identidad profesional, por lo que orientan su desempeño siguiendo patrones de éxito que observan en actores relevantes en su quehacer cotidiano.

\section{Las profesionales con trayectoria consolidada}

Este apartado presenta los hallazgos de los dos grupos de profesionales de la comunicación establecidos desde el posicionamiento teórico y la arquitectura metodológica: comunicólogas y comunicadoras. Las primeras, conforme a la clasificación teórica de Trejo (2010), cursaron estudios en el campo de las ciencias de la comunicación, y las segundas desarrollaron sus estudios en programas ajenos a este campo. A continuación se hace referencia a su incursión al campo laboral, también se abordan las fases de su trayectoria profesional, el reconocimiento de su función social, la conformación de su identidad y la reflexión sobre su condición de género en el campo laboral.

\section{Incursión al campo laboral.}

En el caso de las comunicólogas, su incursión al campo laboral tuvo una estrecha relación con la decisión de estudiar, como primera o segunda opción, la licenciatura en Ciencias de la Comunicación o programas afines. Un sector enfatizó que su decisión se sostuvo irreductible desde el inicio de su formación. Se trata de quienes optaron por esta carrera pensando en que no solo cumplía sus expectativas, sino además las llevaría a incursionar en la profesión de sus sueños. En este sentido, una entrevistada mencionó: "Me gusta y en esa época me gustaba, y veías cómo ven la televisión y decías: 'Pues yo quiero hacer eso', y luego, quieras o no, se te facilita a veces" (5-BT).

Para otro sector, los estudios en CICOM constituyeron una segunda opción, una alternativa temporal, no obstante, al conocer lo concerniente al ejercicio profesional, encontraron en el periodismo su verdadera pasión. Una entrevistada afirmó: 'Yo tenía intenciones de estudiar medicina, no hubo oportunidad (...) entonces me inscribí con la esperanza de estar un tiempecito y después hacer lo que yo quería" (4-BT). Otra señaló: "Yo no quería prensa, periodismo, sin saber que la vida te acomoda en 
el lugar y en el momento preciso, ahora, el periodismo es mi pasión y después de veintitantos años de carrera no sabes cómo la disfruto" (3-BT).

En cuanto a las comunicadoras, su formación académica resultó ajena a este campo ya que cursaron estudios de antropología, literatura hispanoamericana y publicidad, no obstante, se comprometieron con la profesión durante su trayectoria. Su incorporación se dio por factores distintos al interés profesional; en este sentido, una entrevistada refirió:

No tenían conductores, entonces, la que era mi jefa me dice: “¿Por qué no haces una prueba y ve si te gusta?", y bueno, me quedé como la conductora y me di cuenta de que era lo mío, pero no lo había descubierto, si no, hubiera estudiado comunicación en lugar de publicidad [6-BT].

En general, la vocación entendida como el deseo y libre elección por formar parte de un ámbito (Castañeda-Rentería y Solorio-Aceves, 2014) se mostró en dos principales formas: están quienes contaron con una trayectoria profesional consolidada ya que su formación universitaria fue consistente con su incorporación a los medios de comunicación y, por otra parte, se encontró a quienes estudiaron disciplinas distintas a CICOM, y aunque asumieron como temporal su incursión a este campo, se quedaron para consolidarse.

\section{Fases de la trayectoria profesional.}

Las comunicólogas consolidadas, a diferencia del grupo de las pioneras, en su primera incursión encontraron un campo laboral saturado, el cual descubrieron desde el desarrollo de sus prácticas profesionales. Una entrevistada destacó lo siguiente:

Se dio la oportunidad de que pudiéramos realizar prácticas y es enfrentarte a la realidad, recuerdo que se abrió una plaza y venían personas ya con experiencia para poder concursar y fue cuando dije: "No es posible que, habiendo esta oportunidad, por la inexperiencia, por el miedo, por la timidez"... pues desde luego le dieron prioridad a la gente que sabía, y entonces en ese momento fue como un reto para mí involucrarme en las cuestiones periodísticas [3-BT].

Esta etapa representó una oportunidad para conocer diversas actividades en los medios, además de que se trató de la antesala del inicio de su trayectoria profesional, permitiéndoles identificar algunos obstáculos que enfrentaron con los recursos instrumentales y en menor medida con los recursos teóricos obtenidos en la universidad. En torno a este punto, otra entrevistada señaló:

Una cosa es lo que aprendes en la escuela que es casi pura teoría y es práctica nula, comentarios de experiencias de algún profesor de cómo les fue, pero hasta ahí, pero cuando egresas y sales y ves cómo son las cosas, dices [...] "Bueno, tengo que trabajar" y hacer las cosas para sobrevivir $\mathrm{y}$ vivir en el ambiente, porque si no te envuelves en el ambiente, te pierdes [2-BT].

Una vez concluida su vida escolar, las comunicólogas indicaron la existencia de tres factores que motivaron su primera incursión a los medios de comunicación: prestigio, proyección e innovación. Una entrevistada comentó: 
El hecho de estar en el periódico de mayor importancia en ese momento en el estado, pues era lo máximo, y creo que muchos periodistas y egresados, y muchos compañeros se quedaron con esa intención de poder trabajar en el medio de mayor circulación [3-BT].

El prestigio fue el factor que consideraron con mayor énfasis al inicio de su carrera, por lo que buscaron incorporarse al periódico El Sol de Tlaxcala, al cual, en la década de los años noventa, reconocieron como el medio impreso con mayor circulación en la entidad, lo cual en sus imaginarios reflejó estabilidad y la posibilidad de construir una carrera exitosa.

El segundo factor fue de proyección; buscaron espacios para construir las bases de su currículum vitae y al mismo tiempo continuar aprendiendo con un perfil propio, lo cual implicó dejar de laborar en espacios consolidados. En este sentido comentaron:

Busqué una oportunidad de lo que me gustaba, fue en prensa, estuve una corta temporada en la sección Puebla-Tlaxcala [...] de El Universal, aprendí muchas cosas, no me encantó por eso no lo vi como alternativa inmediata para establecerme y ser yo misma [4-BT].

El tercer factor fue de innovación, al respecto una entrevistada afirmó: "Nunca me interesaron otros medios que ya existían, no satisfacían mi necesidad, un medio nuevo no estaba dentro del ámbito político (...) además yo acababa de egresar y no había vicios ni de una ni de otra parte" (10-BT). Un sector decidió acercarse a los medios que estaban instalándose en la entidad ya que no se encontraban comprometidos en algún ámbito político local, por lo que además del ejercicio libre de su pluma, constituyó una oportunidad de estabilidad y crecimiento profesional.

Aún cuando existen diferencias claras entre los tres factores abordados, las entrevistadas coincidieron en asegurar que al inicio y en la fase media de su trayectoria buscaron formar parte de un medio, sin embargo, en su fase madura existió una variación de intereses, encontrándose quienes consolidaron su trayectoria profesional participando en medios impresos, además de radio y televisión, ámbitos en los cuales, afirmaron, seguirán construyendo su vida profesional. Por otra parte, están quienes decidieron fundar su propio medio digital aprovechando el desarrollo tecnológico. Sin duda, aprendieron a emprender y aprendieron a arriesgar, demostrando la pertinencia de ambas competencias que Tünnermann (2003) propuso como complementarias a los cuatro pilares de la educación promulgados por la Organización de las Naciones Unidas para la Educación, la Ciencia y la Cultura (UNESCO, 1996).

Con la creación de sus empresas no solo contribuyeron a la formación de estudiantes de la Universidad del Altiplano, permitiéndoles el acceso a contextos de trabajo reales mediante la instancia de prácticas profesionales, sino además ampliaron las oportunidades laborales para las siguientes generaciones de comunicólogos. También se posicionaron como las primeras mujeres en colocar al periodismo digital en la entidad. Ahora, sus expectativas de éxito profesional las centran en su proyecto 
personal, para el cual continúan formándose. En este sentido señaló una entrevistada: “...me dice: 'Oye (...) te quiero felicitar, eres la única mujer que ha sacado hasta el momento un periódico (...) tú ya lo hiciste, mira, ya andas aquí como toda una empresaria"” (2-BT).

En tanto al grupo de las comunicadoras, por coyunturas encontraron en los medios de comunicación un espacio laboral en el cual se incorporaron suponiendo una estancia temporal, no obstante, asumieron la profesión y en su fase inicial se profesionalizaron en la práctica.

Tuvimos módulos de literatura mexicana, literatura española, literatura occidental, literatura prehispánica, literatura argentina, todo Latinoamérica, fue lo más fuerte, pero también estaban materias de comunicación y todo enfocado a lenguaje, entonces hay una conexión [...] además he tomado cursos ya en periodismo cultural, periodismo electoral, sobre medios masivos de comunicación, la radio como fuente de información, también en televisión, la capacitación ha sido de manera continua y, pues a la par también doy clases [7-BT].

Lograron cubrir los vacíos con los cuales incursionaron, no obstante, estando ya consolidadas, afirmaron que, aún sin contar con las bases profesionales sobre la disciplina, siempre asumieron su labor con compromiso ético-laboral.

\section{La función social como baluarte de la profesión.}

Ambos grupos aseveraron que una trayectoria exitosa también debe ser reconocida por la capacidad de encontrar en los medios de comunicación un puente que promueva la justicia social con los sectores que no encuentran voz entre las estructuras sociales. Una entrevistada comentó:

Nuestra intención, aparte de querer ayudar al propio gremio, en general, hombres y mujeres, es ayudar también al sector vulnerable. Como reporteras te das cuenta de que hay demasiada pobreza, hay gente que necesita, hay carestía en varios lugares y por una u otra razón no acuden a las instancias $[. .$.$] y prefieren quedarse ahí cerradas y no buscar un apoyo como tal [9-BT].$

Enfatizaron que, en un contexto social secuestrado por la sospecha respecto a la integridad de sus instituciones y sus representantes, además del desencanto por la definición de políticas públicas que parecen mantener en el olvido a los grupos vulnerables, su labor se convirtió en un aliciente de esperanza cuando es soportada con compromiso ético-profesional. Una participante señaló:

Me fui a trabajar de obrera, para ver, para vivir en carne propia lo que vivían las obreras, la discriminación; fui contratada sin ningún documento, no me dieron seguridad social, las ocho horas laborales de pie, y yo trataba de platicar con las compañeras para poder sacarles información y no llamar mucho la atención, entonces se evidenció la vida real de una obrera [3-BT].

Se puede observar que su labor constituyó una ventana para sostener en la agenda pública los temas que la mayoría no considera relevantes porque no responden a una 
lógica racional-comercial, por lo que este tipo de esfuerzos para contribuir al cambio social son los que simbolizan mayor valor en su carrera y en ese sentido los enaltecen como referentes de su éxito laboral.

\section{La conformación de la identidad.}

La identidad es un tema que ha sido estudiado ampliamente como concepto, como fenómeno y como característica humana (Coll y Falsafi, 2010; Hernández, 2020), por eso, reconociendo la indefinición semántica que se posiciona sobre sus significados, se decidió recuperar la propuesta de Vergara del Solar, Vergara Estévez y Gundermann (2010), para quienes consiste en el proceso de afirmación de sí mismo, así como de pertenencia y diferenciación en relación a los demás. Se trata de un proceso en permanente construcción que se reconfigura en correspondencia con los momentos y contextos en los cuales las personas interactúan, como tal, siguiendo a Zizek (2003), se manifiesta mediante significantes flotantes que son cohesionados por un punto nodal.

En el marco de la investigación, comunicólogas y comunicadoras comentaron que su identidad es el resultado de un proceso de aprendizaje permanente, soportado en la toma de decisiones, sin embargo, también reconocieron que se mantienen dispuestas a nuevas experiencias ya que así lograron sostener su labor con pertinencia. Una entrevistada planteó:

Estuve siempre cobijada por grandes personas, personas con un alto sentido humano y, bueno, en radio me encontré a [...] ella ya llevaba diez años, me lleva diez años en radio, inició en radio y luego emigró a noticias y yo estuve mucho tiempo colaborando con ella, aprendiendo también de mis compañeros, entonces, siempre he estado muy bien cobijada [7-BT].

El punto nodal se colocó en la disposición para asumirse como profesionales de la comunicación, y en torno a esta disposición se manifestaron diversos factores que como significantes flotantes fueron articulando una definición de sí mismas. Entre los factores se encontró el sistema de valores heredados en su círculo familiar, también el apego a la filosofía de las organizaciones en las cuales participaron, incluso la influencia de figuras que contribuyeron a su formación académica y en el ejercicio de su profesión. Otra entrevistada comentó lo siguiente:

Todo suma, inicias queriendo devorar el mundo, llegas con ideas nuevas y muchas veces te das cuenta de que no eran tan nuevas, así que muchas veces te da el bajón, pero siempre están quienes te animan para seguir; la familia, amigos, los compañeros que no son egoístas y te ayudan a crecer dándote consejos, ya sabes, "esto sî", "por ahí no”, "él es asî", “ella también” [...] la escuela es bonita, pero el trabajo es diferente, es más complicado, es la realidad, y entonces solo queda recuperar lo que sirve, valorar a quienes dejaron algo bueno, los maestros, aprovecharlo, todo y todos aportaron para ser lo que ahora soy [9-BT].

El respeto hacia la profesión, al igual que el compromiso social, resultaron fundamentales para consolidar su identidad, además de su trayectoria. Un reflejo 
de esa condición consistió en el capital lingüístico que se apropiaron en los medios de comunicación, es decir, ambos grupos, aunque con orígenes académicos distintos, adoptaron un sistema de lenguaje, en el cual, después de la fase inicial de su trayectoria, no se encontraron diferencias, sino al contrario, se desarrolló una base de interacción común que heredaron de la dimensión lingüística de su contexto de acción. En este sentido, una comunicadora señaló: "No entendía, hablaban con sus palabras técnicas, pero lo aprendes rápido, tienes que aprenderlo rápido, al último todos nos entendíamos en nuestro lenguaje técnico, es como muy de los medios, es parte de la identidad" (8-B'T).

Acotando, conforme a los fragmentos revisados, es posible percatarse de que en su discurso destacó una narrativa humanista soportada en el compromiso éticoprofesional, conforme al cual, los significantes flotantes que configuraron su identidad correspondieron a su sistema de valores familiares, al capital académico, técnico y axiológico recibido en sus instituciones formadoras, así como al capital instrumental y lingüístico heredado de su gremio. El punto nodal consistió en su vocación, perfilada desde el principio de su trayectoria o una vez inmersas en esta, según corresponda. Al final, su identidad, tal como plantearon Torres y Carrasco (2008), se sostiene abierta a las nuevas dinámicas que se presentan en sus contextos.

\section{La condición de género en la trayectoria profesional.}

Por otra parte, no encontraron en la condición de género un referente que haya limitado o promovido su desarrollo profesional, incluso, aunque fue posible señalar un par de experiencias negativas, estas contrastaron con la voz común que afirma que ser mujer en ninguna forma constituyó un referente negativo ante las instituciones y menos entre los diferentes grupos que conforman a las organizaciones.

Como mujeres, siempre recibieron un trato justo y equitativo que aprovecharon para potenciar su propia capacitación; una informante mencionó: "No tuve discriminación $[\ldots]$ dieciséis años de no tener ningún reporte o un apercibimiento, fue disciplina, y bien padre, porque el jefe de redacción era hombre y cuando mi jefe de información se iba, me dejaban a cargo" (3-BT). El éxito profesional lo atribuyeron a su esfuerzo cotidiano, así como a la capacidad de relación que sostuvieron con ética en un ambiente laboral, en el cual tanto hombres como mujeres se esfuerzan por construir una carrera que les permita colocarse como referentes de la comunicación en el espacio público.

En tanto a las experiencias negativas, la primera consistió en la discriminación de una conductora cuya imagen no correspondía a las expectativas del área de producción, ante lo cual, atribuyendo descuido en su persona, fue condicionada para responder a la demanda de sus jefes, pero al no hacerlo en el tiempo estipulado fue separada del programa. El otro caso se presentó en la conducción de un programa, en el cual, 
en forma reiterada, la comunicadora fue relegada a una figura complementaria de la presencia de su compañero, incluso esto se reflejó en la desigual percepción de salarios. Se comentó lo siguiente:

Toda la vida que he trabajado a la par con hombres siempre ganan más que yo, ¿por qué? No sé, o sea, yo pregunto y digo a ver por qué tiene otro sueldo, y pon tú que es nada, pero es mayor, y entonces digo: "Bueno, pues, esta sociedad" [6-BT].

Ambos casos, aunque no representaron una constante, fueron contextualizados como parte de las intenciones de cambio promovidas por la agenda de Beijing de la cual México participa, así que este tipo de prácticas deben ser erradicadas ya que promueven una visión estereotipada de la mujer, así como la escasa valoración de su condición humana y de su capacidad intelectual.

\section{La universidad y el campo laboral.}

Antes de que en 1986 fuera creada la Escuela de Periodismo Modesto González Galindo, en el estado de Tlaxcala no existía ninguna escuela que formara periodistas profesionales. Su apertura constituyó el legado de la comunicóloga pionera con mayor éxito profesional en la entidad, cuyo propósito se enfocó en habilitar periodistas para que de forma profesional ejercieran su labor, por lo que, en primera instancia, la propuesta curricular se orientó hacia la profesionalización de quienes en esa época laboraron en los medios locales sin una formación adecuada (Hernández, 2017).

Considerando una serie de cambios estructurales y curriculares, la Escuela de Periodismo en el año 2004 pasó a constituirse como Universidad del Altiplano. Se trata de la primera institución de educación superior privada que se creó en la entidad y también fue la primera en ofertar la licenciatura en Ciencias de la Comunicación, programa educativo que es reconocido como el de mayor trascendencia y también como el primero en formar especialistas en comunicología, lo que implicó la modificación curricular que de origen se orientó a la formación de periodistas.

En este marco, las mujeres entrevistadas en principio reconocieron a la Escuela de Periodismo Modesto González Galindo (Universidad del Altiplano) como la única casa de estudios que ha preparado comunicólogos en la entidad, por lo que, en el ejercicio de su profesión, el campo laboral local se vio impactado por las 27 generaciones de profesionistas que han egresado desde su fundación. Es una universidad pionera con un programa pionero que en el año 2010 fue acreditado por el Consejo de Acreditación de la Comunicación A.C. (CONAC), el cual forma parte de los organismos reconocidos por el Consejo para la Acreditación de la Educación Superior (Copaes) (Hernández, 2017; UDA, 2020).

Las comunicólogas entrevistadas, en su mayoría, reconocieron a esta institución como su alma mater, y las comunicadoras destacaron su trascendencia en la entidad, 
afirmando que en el gremio se asume que los comunicólogos que incursionan llegan con altas probabilidades de ser, como ellos se denominan, Comunidad UDA. Una entrevistada comentó: "Aparecen bloques de jóvenes de veinte años, veintiún años, con todas las ganas, con todo el ímpetu, con todo el deseo de conocer, de trabajar, de aprender, de comerse el mundo en Tlaxcala" (2-BT). Otra más señaló: "Sabes que vienen de la UDA, las reconoces, muy pocas vienen de instituciones de fuera, por ejemplo, Puebla; sabes que la UDA es la fuente natural de comunicólogos en el estado" (3-BT).

Considerando que esta universidad ha sido por más de tres décadas el semillero de profesionales de la comunicación, podemos afirmar que su crecimiento también ha sido un indicador del desarrollo de este campo laboral en Tlaxcala, nutriéndose en forma recíproca. Una entrevistada señaló: "Regresas a tu alma mater, ahora como ejemplo, y uno les platica lo que pasamos y lo que ahora hacemos, pero cada uno tendrá que recorrer su camino y seguramente les tocará regresar" (4-BT). También comentó otra entrevistada: "Siempre da gusto regresar, ahí fui estudiante y ahora me invitan a darles charlas, conferencias, clases" (2-BT). La posibilidad de retornar como especialistas, lo asumieron como un reconocimiento a su trayectoria ya que en ese momento tienen la oportunidad de retribuir parte de la formación que en su momento recibieron, pero además de esta condición, también deja ver el retorno de comunicólogas en una nueva faceta, es decir, ahora como formadoras que, desde su doble condición, como egresadas y profesionistas conocedoras del campo laboral, regresan a su alma mater para formar a las nuevas generaciones. En general, los diferentes fragmentos recuperados muestran una relación de cimentación mutua entre el gremio de comunicólogos y la Universidad del Altiplano, que se estableció como la primera institución de educación superior privada y como bastión en la formación de egresados con este perfil profesional

\section{Conclusiones}

Las mujeres que incursionaron en los medios de comunicación pueden clasificarse en tres perfiles: pioneras, de trayectoria consolidada y noveles. Las pioneras fueron quienes se incorporaron en momentos en los que no existían muchos medios de comunicación en la entidad, por lo que también la participación de la mujer en este ámbito se desarrolló de forma acotada. Les correspondió la tarea de abrir el horizonte profesional, no solo por su participación laboral sino, incluso, por su legado, destacando la creación de la Universidad del Altiplano, la cual oferta el programa con mayor prestigio en la entidad en el campo de las Ciencias de la Comunicación.

En cuanto a las mujeres con trayectoria profesional consolidada, siguiendo la propuesta de Freidin (1996), fue posible identificar dos grupos: en el primero se 
encuentran las comunicólogas, es decir, quienes estudiaron Ciencias de la Comunicación o programas afines, y en el segundo están las comunicadoras, mujeres que no estudiaron un programa afín al campo de la comunicación (antropología y literatura hispanoamericana), no obstante, mostraron compromiso ético-laboral en su quehacer cotidiano.

Las comunicólogas con trayectoria consolidada son herederas del legado de las pioneras y asumieron con compromiso ético-profesional la labor iniciada por ellas. Les tocó vivir la transición de los medios tradicionales hacia los medios digitales, lo cual aprovecharon para crear su propio espacio laboral. Las comunicadoras noveles encontraron en ellas sus referentes de éxito.

En cuanto a la conformación de su identidad, entendida como la afirmación de sí mismas, manifestando sentido de pertenencia y diferenciación con relación a los demás (Vergara, Vergara y Gundermann, 2010), fueron identificados cuatro ejes que influyeron tanto en las comunicólogas como en las comunicadoras: el sistema de valores personales construido desde sus familias, la herencia de quienes incursionaron en primera instancia en los medios de comunicación, la formación profesional recibida en la universidad y el capital cultural y lingüístico construido en su contexto laboral. En conjunto, determinaron la forma en que asumieron su compromiso social. En cuanto al grupo con trayectoria laboral exitosa, además, la conformación de su identidad se vio altamente impactada por la profesionalización construida a partir del contacto con los colegas de su gremio.

Comunicólogas y comunicadoras asumieron una actitud emprendedora en la transición de los medios con formato tradicional hacia las propuestas digitales, y en algunos casos esto constituyó la base para construir su propia compañía. Cuando les ha sido posible, ambos grupos dotan su labor de un carácter crítico, convirtiendo a los medios en un espacio propicio para contribuir a la justicia social, dando voz a los grupos vulnerables.

En cuanto a casos adversos, fueron exiguos, por lo que no encontraron en la condición de género un referente que haya limitado o promovido su desarrollo profesional, no obstante, coincidieron en la necesidad de no permitir cualquier posible manifestación de discriminación hacia las mujeres.

La Universidad del Altiplano fue la primera institución privada y también fue la primera que ofreció la carrera de periodismo y la licenciatura en Ciencias de la Comunicación en Tlaxcala (UDA, 2020), por lo que se instituyó como la fuente de profesionistas, quienes ejercen su labor poniendo en práctica el capital intelectual e instrumental construido en su estancia universitaria, mismo que implementan a través de una dialéctica que los coloca como referentes obligados de consulta en los procesos de fortalecimiento curricular que se desarrollan en el programa educativo del cual formaron parte, empoderándose mutuamente. 
Finalmente, los hallazgos que derivan de este trabajo constituyen un punto de partida para continuar comprendiendo a los perfiles pionero y noveles de las mujeres que han conformado el campo de la comunicación en Tlaxcala, así que se espera que contribuyan al desarrollo de investigaciones posteriores que desde diferentes tradiciones epistémicas y metodológicas aporten a la construcción de nuevos sentidos al tema.

\section{REFERENCIAS}

Alós-Moner, R. (2008). Segmentación de los mercados de trabajo y relaciones laborales. El sindicalismo ante la nueva acción colectiva. Monográfico: Globalización y Sindicalismo, 26(1), 07-23. Recuperado de: https:// revistas.ucm.es/index.php/CRLA/issue/view/ CRLA080812.

Aparici, A. (2004). Seguimiento de las trayectorias ocupacionales de los titulados por las universidades Jaume I de Castellón, Valencia (E.G) y Alacant. España: Publicaciones de la Universidad Jaume I.

Arango, G. (2006). Jóvenes sociólogos/as e ingenieros/ as de sistemas en la Universidad Nacional: origen de clase e identidad social. En G. Arango (coord.), Jóvenes en la universidad. Género, clase e identidad profesional. Colombia: Siglo del Hombre Editores/Universidad Nacional de Colombia.

Blanco, E., Solís, P., y Robles, H. (Coord.) (2014). Caminos desiguales. Trayectorias educativas y laborales de los jóvenes en la Cindad de México. Recuperado de: https://historico. mejoredu.gob.mx/wp-content/uploads/2019/01/ P1C230.pdf.

Bourdieu, P. (1998). Razones prácticas. Sobre la teoría de la acción. Barcelona: Anagrama.

Burkle, M. (1997). La post-televisión y la construcción de la sexualidad de la mujer. Razón y Palabra. Edición especial. Recuperado de: http://www.razonypalabra. org.mx/mcluhan/post.htm.

Caballero, M., y García, P. (2007). Curso de vida y trayectoria de mujeres profesionistas. México: El Colegio de México.

Casal, J. (1996). Modos emergentes de transición a la vida adulta en el umbral del siglo XXI: aproximación sucesiva, precariedad y desestructuración. REIS, 75(96), 295-316. Recuperado de: https:// dialnet.unirioja.es/ servlet $/$ articulo?codigo $=761453$.

Castañeda-Rentería, L., y Solorio-Aceves, M. (2014). La elección de carrera: entre la vocación y las ofertas institucionales. Revista de Educación y Desarrollo, (28), 55-59.
Recuperado de: http://www.cucs.udg.mx/revistas/ edu_desarrollo/anteriores/28/028_Castaneda.pdf.

Coll, C., y Falsafi, L. (2010). Presentación. Identidad y educación: tendencias y desafíos. Revista de Educación, (353), 17-38. Recuperado de: http://www.educacionyfp.gob.es/dam/jcr:35caafff-73be-4802-955f6320971d89f6/re35301-pdf.pdf.

Delors, J. (1996). La educación encierra un tesoro. España: UNESCO.

Filardo, V. (2016). Integralidad en el análisis de trayectorias educativas. Educación y Realidad, 41(1). Recuperado de: https://www.scielo.br/scielo.php?script $=$ sci_ arttext\&pid=S2175-62362016000100015\&lng=es\& tlng=es.

Freidin, B. (1996). Trayectorias laborales, conceptos y valores sobre el trabajo de mujeres migrantes pobres. Argentina: Edit. Instituto Gino Germani/Universidad de Buenos Aires.

Gadamer, H. (2007). Verdady método. España: Sígueme.

García, N., y Martínez, L. (2008). La percepción de la imagen de las mujeres en los medios: una aproximación cualitativa. Comunicación y Sociedad, (10), 111-128. Recuperado de: http://www.scielo.org. $\mathrm{mx} /$ scielo.php? script $=$ sci_arttext\&pid $=$ S0188252X2008000200005.

Granados, R., Tapia, A., y Fernández, J. (2017). La construcción de la identidad de los docentes noveles: un análisis desde las teorías apriorísticas. Revista de Docencia Universitaria, 15(2), 163-178. Recuperado de: https:/ / dialnet.unirioja.es/servlet/articulo?codigo $=6276892$. Guerreiro, M., y Abrantes, P. (2005). Transiciones a la vida adulta en la era de la globalización. Recorridos de incertidumbre. RECERCA, (5), 63-86. Recuperado de: http:/ /www.e-revistes.uji.es/index.php/recerca/ article/view/238.

Hernández, A. (2017). Identidad de estudiantes en la Universidad del Altiplano en Tlaxcala: una aproxi- 
mación. En Paz Diéguez (coord.), Jóvenes estudiantes de educación superior: reflexiones desde la experiencia universitaria (pp. 91-116). México: BUAP.

Hernández Vélez, A. (2020). La identidad epistemológica de los estudiantes de doctorado en educación. IE Revista de Investigación Educativa de la REDIECH, 11, e816. Recuperado de: https://www.rediech.org/ojs/2017/ index.php/ie_rie_rediech/article/view/816.

IMCO [nstituto Mexicano para la Competitividad] (2020). Compara carreras 2019. Recuperado de: https:/ imco.org. $\mathrm{mx} /$ compara-carreras-2019/.

INMujeres [Instituto Nacional de las Mujeres] (2017). ¡Fuera estereotipos! La igualdad también se gana en los medios de comunicación, 16-18. Ciudad de México.

INEGI [Instituto Nacional de Estadística y Geografía] (2017). Base de datos. Recuperado de http:// www3.inegi.org.mx/sistemas/temas / default. aspx?s $=$ est\&c $=25433 \& \mathrm{t}=1$.

Jiménez, M. (2009). Teoría y hallazgos en los estudios de trayectoria: una opción metodológica para clasificar el desarrollo laboral. Revista Electrónica e Investigación Educativa, 11(1). Recuperado de: https://redie.uabc.mx/redie/ article/view/216.

Julia, A. (2018). Las trayectorias educativas de hombres y mujeres jóvenes. Una aproximación desde el análisis de secuencias. Revista de Sociología, 103(1), 5-28. Recuperado de: https://papers.uab.cat/article/view/v103-n1julia/2290-pdf-es.

Kvale, S. (2011). Las entrevistas en investigación cualitativa. España: Morata.

Loscertales, I., y Núñez, T. (2009). La imagen de las mujeres en la era de la comunicación. Revista Científica de Información y Comunicación, (6), 427-462. Recuperado de: http:// institucional.us.es/revistas/comunicacion/6/4.2\%20 Loscertales.pdf.

Merleau-Ponty, M. (1994), Fenomenología de la percepción. España: Planeta-Agostini.

Ministerio del Trabajo y Previsión Social (2017). Informe de trayectorias laborales. Evaluación de implementación de programas subsidio al empleo joven y bono al trabajo de la mujer año 2016. Chile: ARS.

Montes, M., Castillo, E., y Oliveros, L. (2017). Rasgos identitarios del profesor novel en educación superior en México: perfil socio-académico y formación recibida en la fase de inserción. Ponencia presentada en el XIV Congreso Nacional de Investigación Educativa-COMIE, San Luis Potosí, México. Recuperada de: http://www.comie.org.mx/congreso/memoriaelectronica/v14/ doc/1711.pdf.

Muñiz, L. (2012). Carreras y trayectorias laborales: una revisión crítica de las principales aproximaciones teórico-metodológicas para su abordaje. Revista Latinoamericana de las Ciencias Sociales, 2(1), 33-65. Recuperado de: http://www.memoria.fahce.unlp. edu.ar/art_revistas/pr.5218/pr.5218.pdf.

Neffa, J., De la Garza, E., y Muñiz, L. (comps.) (2009). Trabajo, empleo, calificaciones profesionales, relaciones de trabajo e identidades laborales. CLACSO. Recuperado de: http://biblioteca.clacso.edu.ar/clacso/ gt/20100625114604/neffa1.pdf.

ONU [Organización de las Naciones Unidas] (1996). Declaración y Plataforma de Acción Beijing. ONU, 171-177. Recuperado de: https://www.unwomen. org/-/media/headquarters/attachments/sections/csw/bpa_s_final_web.pdf?la $=$ es\&vs $=755$.

Ortiz, M. (2001). Igualdad de sexos en los medios de comunicación. En M. Queizán (coord.), Mujeres en medio: repaso crítico a los medios de comunicación y su lenguaje (pp. 97-116). España: AMECO.

Oshige, D. (2016). Reciclando oficios: trayectorias de vida y percepciones de los recicladores en Lima Metropolitana. PUCP La Colmena, (9), 32-47. Recuperado de: http://revistas.pucp.edu.pe/index. php/lacolmena/article/view/19030/19244.

OIT [Organización Internacional del Trabajo] (2017). Plan de acción de la OIT sobre igualdad de género. Recuperado de: https://www.ilo.org/gender/Informationresources/WCMS_545493/lang—es/ index.htm.

Secte [Secretaría de Comunicaciones y Transportes] (2019). Sección de observación, análisis y alerta. Recuperado de: http://www.proteccioncivil.gob.mx/ work/models/ProteccionCivil/swbcalendario_ ElementoSeccion/89/06_1_SECCION_DE_OBSERVACION_ANALISIS_Y_ALERTA_2014. PDF.

Trejo, R. (2010). Comunicólogos y comunicadores. Entre la torre de marfil y el torrente mediático. Universidades, (47), 8-19. Recuperado de: https:/ / www.redalyc.org/pdf/373/37318570003.pdf. 
Tünnermann, C. (2003). Constructivismo y reforma curricular. México: Universidad Autónoma de Tlaxcala.

UDA [Universidad del Altiplano] (2020). Nuestra universidad. Recuperado de: https://universidaddelaltiplano. com/uda/.

UNESCO [Organización de las Naciones Unidas para la Educación, la Ciencias y la Cultura] (1996). Informe Delors: la educación encierra un tesoro. España: UNESCO. Valenti Nigrini, G., Varela Petito, G., Gonzalez Robles, R., y Zurita Rivera, U. (coords.) (1997). Los egresados de la UAM en el mercado de trabajo. Investigación evaluativa sobre la calidad de la oferta de servicios educativos. Recuperado de: https://core.ac.uk/download/pdf/48392409.pdf.
Velázquez, L. M. (2007). Preparatorianos: trayectorias y experiencias en la escuela. En C. Guzmán y C. Saucedo (coords.), La voz de los estudiantes. Experiencias en torno a la escuela (pp. 44-68). México: UNAM-CRIM/ Ediciones Pomares.

Vergara del Solar, J., Vergara Estévez, J., y Gundermann, H. (2010). Elementos para una teoría crítica de las identidades culturales en América Latina. Utopía y Praxis Latinoamericana, 15(51), 57-79. Recuperado de: https://www.redalyc.org/pdf/279/27916299005. pdf.

Zizek, S. (2003). El sublime objeto de la ideología. Argentina: Siglo XXI Editores.

Cómo citar este artículo:

Hernández Vélez, A., y Montiel Meléndez, M. (2021). Universidad y campo laboral: las mujeres en el ámbito de la comunicación. IE Revista de Investigación Educativa de la REDIECH, 12, e907. doi: https:/ /doi.org/10.33010/ie_rie_rediech.v12i0.907. 